\section{Control, aprendizaje y oposición: la experiencia escolar en casa durante la pandemia}

\author{
ALBERTO T. ALONSO SARMIENTO ${ }^{1}$ \\ 0000-0002-9789-2783 \\ Universidad Autónoma Metropolitana, México
}

JAZMÍN CUEVAS PINEDA²

0000-0003-0134-9047

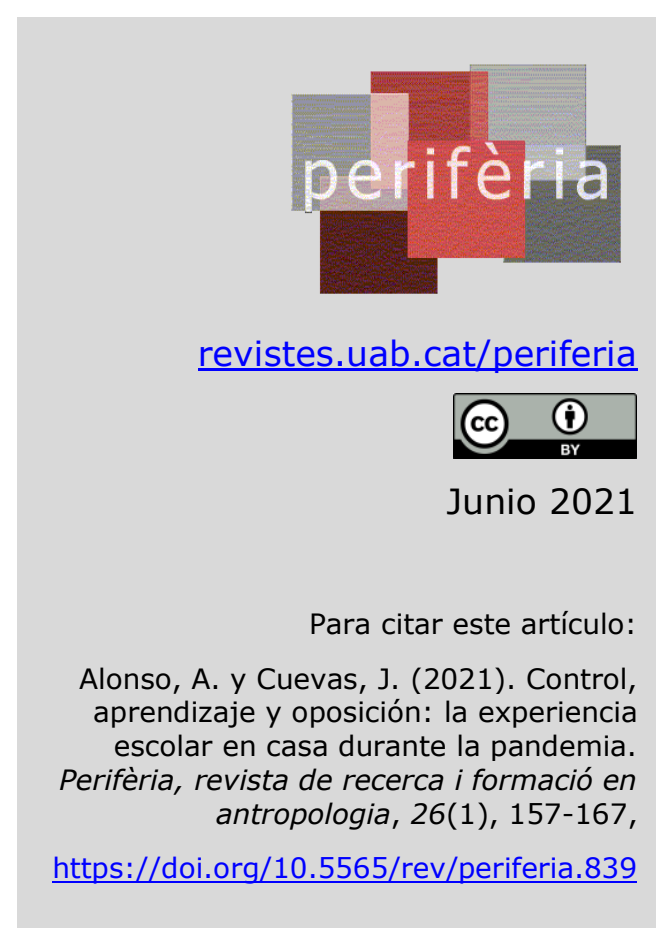

\title{
Resumen
}

La pandemia por covid-19 llevó al Estado mexicano a implementar diversas medidas para evitar los contagios, como el cierre de las escuelas. El objetivo de este trabajo es exponer la experiencia escolar en casa de un par de familias en condiciones de vulnerabilidad, así como dar cuenta de la reconfiguración consecuente en las relaciones e interacciones que sostienen. Tras la realización del trabajo etnográfico, consistente en observación participante, entrevistas, conversaciones informales y fotografía, se concluye que la experiencia escolar en casa se desarrolla mediante procesos de dominación que resultan en aprendizajes, pero también en oposición.

Palabras clave: Pandemia; Interacción; Aprender en casa; Control; Oposición.

\begin{abstract}
Control, learning and opposition: the home school experience during the pandemic

The covid-19 pandemic led the Mexican State to implement various measures to prevent contagion, such as the closure of schools. The objective of this work is to expose the home school experience of a couple of families in vulnerable conditions,
\end{abstract}

\footnotetext{
${ }^{1}$ Contacto: Alberto Tonatihu Alonso Sarmiento - beto 420@hotmail.com

${ }^{2}$ Contacto: Jazmín Cuevas Pineda - jazmin.docente.ms@gmail.com
} 
as well as to account for the consequent reconfiguration in the relationships and interactions they sustain. After the ethnographic work, consisting of participant observation, interviews, informal conversations and photography, it is concluded that the school experience at home is developed through processes of domination that result in learning, but also in opposition.

Keywords: Pandemic; Relationships; Learning at home; Opposition; Control.

\section{Introducción}

Las experiencias durante la pandemia en México se viven en la incertidumbre. No se sabe cuántos serán los contagios que se registrarán en el día, ni tampoco a qué hora terminará la jornada laboral que se ha trasladado a casa. Para quienes no han podido resguardarse en casa por condiciones de vulnerabilidad, se desconoce si las autoridades permitirán la instalación del puesto ambulante. Lo que sí se conoce es que las escuelas están cerradas, y que los hijos tendrán actividades que realizar y evidenciar finalizando el día.

Las experiencias durante la pandemia son atravesadas por la experiencia del traslado de actividades escolares fuera de la propia escuela para la continuidad del aprendizaje. ¿Cómo es que la experiencia escolar trastoca las interacciones que se desarrollan en casa? Para responder, había que observar la experiencia escolar en casa. Para ello, se realizó observación participante, entrevista y conversación informal, así como fotografía en un municipio del Estado de México, ubicado en la periferia de la Ciudad de México, la zona más poblada del país y la más afectada por la pandemia. Se siguió a dos familias que no han podido refugiarse totalmente, además han llevado la experiencia escolar a casa de una de ellas (criterio establecido). ${ }^{3}$ La observación se centró en las interacciones de las personas adultas y las estudiantes que median la relación entre estas últimas y el profesorado. Con las entrevistas y conversaciones informales se profundizó en la experiencia, mientras que con la fotografía se buscó retratarla.

\footnotetext{
3 Para ambas familias, nuestro agradecimiento. Nos abrieron las puertas de su casa mientras, desde el poder, se insistía en refugiarse en ella, evitando el contacto con otros. Y aprendimos igual de ellas.
} 
Los datos se relacionan con la problematización que diversos autores hacen de la pandemia y sus efectos. Se hace eco de investigaciones empíricas que han dado cuenta de las relaciones en la pandemia. Para darle profundidad a los datos, se dialoga con teorías de la escolarización y los aprendizajes que resultan, siendo claves los planteamientos de disciplina de Foucault (2016), de la reproducción social de Bowles y Gintis (1981), de aprendizaje situado mediados por la interacción (Rogoff, 1993), y de oposición (Giroux, 2004).

\section{Condiciones para acondicionar la casa y aprender en ella}

La pandemia tomó desprevenidos a todos. En México, las noticias sobre la situación ocurrida en China, y después en occidente se leyeron a la distancia, como una experiencia de otros. El reporte del primer caso de enfermedad en el país, puso el tema en el discurso político, mas no en las conversaciones cotidianas. Fue el anuncio gubernamental del cierre de las escuelas lo que modificó las cosas. El confinamiento según la experiencia europea nunca llegó; no era necesaria la policía ni el orden jurídico, pues las restricciones a la movilidad podían darse cerrando las escuelas. $Y$ es que el sistema escolar, uno de los más grandes del mundo, cuenta con cerca de 40 millones de estudiantes y docentes; 1 de cada 3 mexicanos participa en él, aunque el registro puede ampliarse a 1 de cada 2 de considerar a sus familias.

Si, como indica Harvey (2020), el sistema político capitalista de corte neoliberal no está preparado para atender la pandemia en su dimensión inmediata, la salud, tampoco su sistema escolar para la realización de actividades escolares en casa. Aprender en casa enfrenta límites cuando solo el $44.3 \%$ de la población dispone de equipos de cómputo y el $70.1 \%$ puede acceder a internet (INEGI, 2020). El condicionamiento es mayor para los hijos de más de la mitad de la población económicamente activa que, en tanto sus padres laboran en la informalidad (no pueden resguardarse), no cuentan con el acompañamiento familiar para aprender en casa según la experiencia escolar.

Si en el norte la emergencia de la pandemia advirtió desigualdades (Fontana, 2020), en el sur, la emergencia en la emergencia (De Sousa, 2020) representó que sus condiciones, de por sí desiguales, fueran todavía más desiguales. Sin resguardo, hay quienes tampoco pueden aprender en casa. Andrés dice: 
Entré a trabajar como al mes de la suspensión [de clases...] tuvimos una situación difícil y no me quedó de otra [...] los maestros me piden los trabajos [...] creo que voy reprobando, pero pues sí está muy difícil [...] llego muy cansado.

Es una pandemia de clase, de género y de etnia (Harvey, 2020), entonces la experiencia de aprender en casa se atraviesa por estas categorías. La fuerza de trabajo constituyente de la primera línea para la atención médica tiene las mismas características que aquella que sostiene los procesos para la realización de actividades escolares en casa: es femenina. Por un lado, las docentes, mayoría en el sistema escolar, aunque subordinadas por tomadores de decisiones varones (en su mayoría), dan las instrucciones. Por otro, las mujeres asumen el acondicionamiento de la casa (o el de algún otro espacio como el puesto del mercado) para que aquellas se hagan. Todo mientras son condicionadas por sus empleos (teletrabajos o no), por su condición de ama de casa o por ambos.

El Estado como técnica de poder y de saber proyecta esquemas sobre la sociedad y sobre los cuerpos mismos, particularmente disciplinados (Foucault, 2016), estableciendo relaciones para la dominación. A través de esas relaciones, el poder, que ofrece recompensas mediante instituciones como la escuela (la promesa de movilidad social), termina haciéndose cuerpo, favoreciendo su operación como prácticas y discursos. Así, la mujer "cuidadora" es una fuerza que facilita tanto el consumo de servicios, como el control de recursos a usarse según el poder mismo. La "mamá", desempleada durante los primeros meses de pandemia hasta que empezó a hacer la limpieza en casa de algunos de sus familiares docentes, señala sus razones para proporcionar tecnologías, espacio, tiempo y cuerpo para la realización de actividades escolares en casa:

Tan solo tomar clases por Zoom o Meet es así como "yo ya no quiero tomar clase", ahora, tienes que lidiar con eso ¿no? ¿Cómo le haces para que tome la clase? Y que además, entienda que tiene que cumplir [...] platicaba con ellas y les decía "el bien no es para mí, es para ustedes"

Si la experiencia escolar en casa es posible a pesar de condiciones de vulnerabilidad, las interacciones en ella deben haber sido reconfiguradas. 


\section{Las interacciones en la casa para aprender en casa}

La realización de actividades escolares en casa inicia con las instrucciones del profesorado, que llegan a través del celular de la "mamá" o de las niñas. Se le requiere también cuando hay que "investigar". Incluso, la televisión se usó un tiempo. Todo termina cuando la actividad es lograda y su evidencia es enviada.

En el proceso, la "mamá" juega un papel central: interpreta mensajes de las profesoras, explica si es necesario, acompaña la realización de las actividades, revisa y manda evidencias. Además, organizó su casa, habilitando la sala como "aula", el "burro" de planchar en estante, una mesita para acomodar mochilas y las ventanas de su cocina en "reloj checador" para la entrega de evidencias. Incluso fijó los horarios de las niñas, ya sea que vivan ahí, sus dos hijas que estudian la primaria, o que se incorporen, sus tres "sobrinas" (hijas de su "hermano", quienes viven con su "abuela", madre de la "mamá", en un domicilio distinto, ubicado en el mismo municipio) que estudian tanto primaria como secundaria. La "mamá" ha convertido su casa en una verdadera escuela mexicana. ${ }^{4}$ De ahí que en las conversaciones de las niñas figuren representaciones de la escuela: "ya nos vamos a la escuela", le indicaban las "sobrinas" a la "abuela" previo a emprender su camino a la casa de la "mamá". Incluso se advierten entre ellas, "iapúrate que tienes clase!".

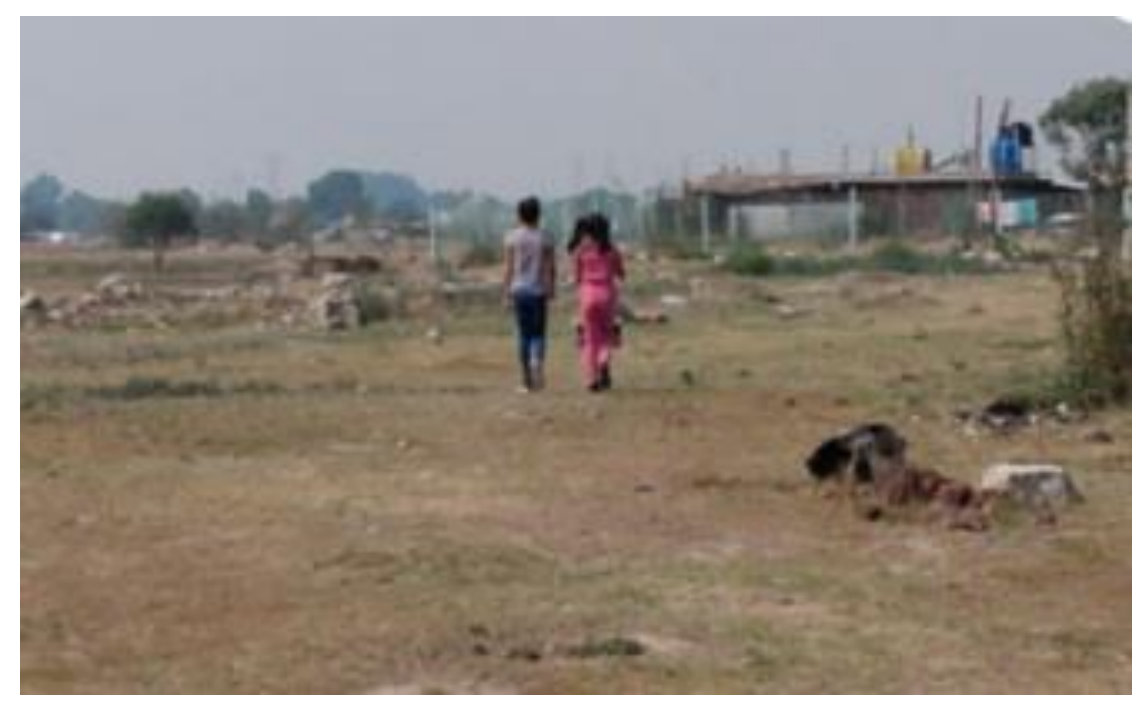

${ }^{4}$ Es una escuela multigrado, como casi la mitad de las primarias mexicanas. 
Imagen 2: "Caminito" a la escuela... durante la pandemia. Jazmín Cuevas, 2020.

Dedicarse a las actividades escolares con las niñas entorpece la realización de otras actividades de la "mamá", como el cuidado de la misma casa, o acudir al empleo. Pero ella y la "abuela" repartieron tareas: la primera, en su casa, se encarga de acompañar a las niñas, incluidas las "sobrinas", mientras que la segunda, en la suya, prepara los alimentos para todas; "es una con otra", se dicen entre las adultas. Esta repartición alcanza también a las niñas, pues ejecutan labores de limpieza de la casa por las tardes. La cooperación femenina entre adultas y niñas se enmarca por la "ausencia" del "hermano", la cual resulta de mandatos patriarcales y no solo de su imposibilidad para resguardarse. La división sexual del trabajo es la única que no ha sido alcanzada por la pandemia.

Por el contrario, la sociabilidad se reestructura de acuerdo a los tiempos que requiere aprender en casa. Previo a la pandemia, ambas familias convivían por las tardes, durante la comida. Esto sigue ocurriendo, pero ahora las niñas conviven mientras realizan las actividades escolares y cuando son responsables de la limpieza de la casa y del cuidado de las mascotas. La convivencia entre adultas y niñas se remite a la escuela y es limitada si se trata de otras experiencias.

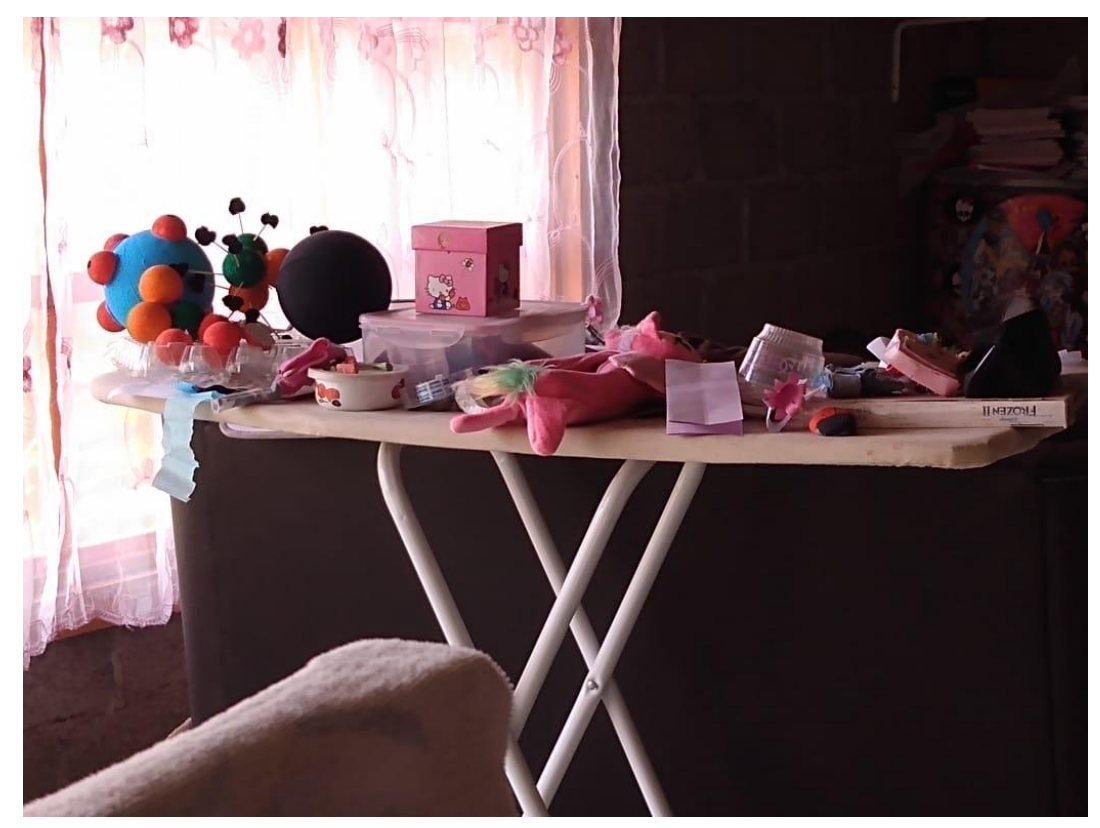

Imagen 3: El burro como estante. Jazmín Cuevas, 2020. 
Así, espacio, tiempo y hasta cuerpo se organizan según la realización de actividades escolares en casa. Lo mismo ocurre con las interacciones, si bien se abren otras formas no experimentadas. Aprender en casa se inserta en estas reconfiguraciones.

\section{Aprendizaje y oposición en casa}

Tras semanas de actividades escolares en casa, una "sobrina" dijo que no había aprendido "nada" de lo realizado. "La mamá" recordó que una de sus hijas, molesta por el exceso de trabajo, le dijo "ni estoy aprendiendo nada aquí". Pero la situación es distinta para ella:

Los días que no les habían dejado tarea, nos levantábamos hasta las diez y media, estábamos ahí echando la hueva y ahora no, nos obligamos a levantarnos, yo me levanto a las siete y ellas, ocho y media, a las nueve están desayunando, ya se nos hizo un hábito, eso nos ayuda.

Realizar actividades escolares en casa implica el aprendizaje para la formación de hábitos. Igual aprender a organizarse según un sentido útil del tiempo, pues dicha actividad debe estar lista para evidenciarse el mismo día:

Entonces con la maestra de "Ana", trabajo no enviado a la hora, no cuenta y (...) eso nos pone en la "torre" a nosotras porque pues lo hacemos, pero no está registrado y es tiempo que ya perdimos".

Este aprendizaje resultó también en una intervención en el espacio que precedió a la reorganización de la "mamá" y las niñas. Así, la primera dispuso un recordatorio de horarios de envío. Su utilidad para proceder efectivamente no sólo es reconocida por ella, sino que se observa en la interacción de las niñas, quienes mantienen una vigilancia tanto al reloj checador como al mismo reloj; cuando el tiempo límite se acerca, la alerta opera: "no manches "Fernanda", ya se te va a pasar la hora; iapúrate!". 


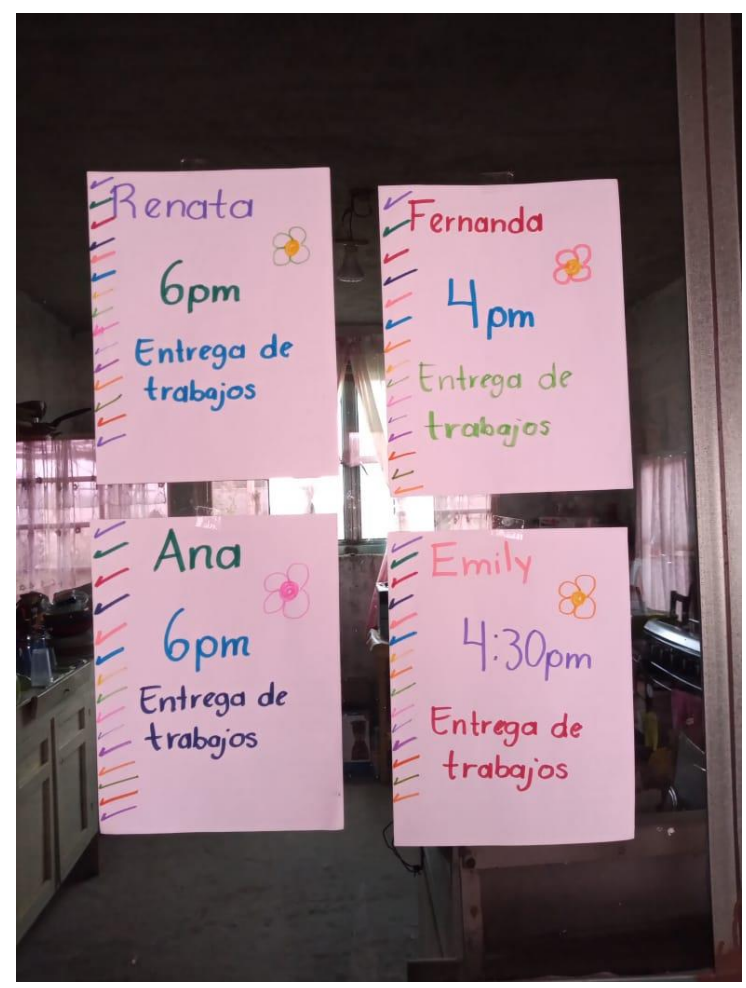

Imagen 4: Reloj checador para la evidencia. Jazmín Cuevas, 2020.

Al menos en esta casa, la escuela y su perspectiva bancaria ha fracasado en cuanto al logro de aprendizajes del currículum formal. No así la interacción entre "la mamá" y las niñas y la socialización que produce. La primera estructura el espacio y el tiempo que favorecen aprender en casa, mientras que las segundas, como sujetos activos del proceso educativo y teniendo a la "mamá" como guía, participan en él, asumiendo modelos, valores e ideas que se esperan de ellas en su propia cultura (Rogoff, 1993) o, al menos en su familia, como "estudiar", según la "abuela".

Los aprendizajes resultantes de esta interacción corresponden al currículum oculto. Si aprender en casa parece organizarse para la producción, pues se realizan actividades escolares a evidenciar para su registro, los aprendizajes logrados deben corresponderle. La disciplina no sólo es útil en tiempos de pandemia para reducir la movilidad; lo es también como actitud que favorece el consumo (de tecnologías) y para el trabajo presencial o virtual (Bowles y Gintis, 1981). Esto último es el argumento de Foucault (2016) tantas veces obviado: el control dispuesto por instituciones como la escuela deviene del desarrollo de las fuerzas productivas. 
Empero, la dominación nunca es completa, y si bien pretende imponerse, controlando, siempre quedan resquicios para oponerse; espacios que resultan de la cotidianeidad y que son inaccesibles o de nulo interés para el poder, por lo que favorecen otras interacciones, valores y sentidos (Giroux, 2004). Cuando la "mamá" los reconoce, procura su cancelación en pro del cumplimiento:

Cuando tienen mucha tarea, no puedo salir al mandado, porque las dejas tantito y, como son chicas todavía [...] regresas y en lugar de estar haciendo tarea, están jugando, riéndose, tomándose fotos, entonces, sí necesitan que esté uno: "a ver, apúrate, ándale y hazle, y a ver qué tienes que hacer aquí.

Mas los espacios perviven y se articulan con otros. Es el caso de aquel que se abre tras aprender en casa: cuidando a las mascotas. Ahí, lejos del poder en tanto espacio cotidiano, las niñas interactúan y practican valores como la solidaridad. Así, si una de las mascotas de las "hijas" necesita cuidados y ellas no están, las "sobrinas" pueden hacerlo, y viceversa. No es para menos; la vida está de por medio. Y es en esta articulación cuando la solidaridad se reviste de sororidad, pues la cooperación que las niñas se brindan igualmente al realizar actividades escolares en casa resulta en el cuidado, aunque de sí mismas. Se cuidan entre sí, colectivamente, tanto para entregar la actividad, como para "acompañar" a quien, fastidiada por el trabajo, no sólo no aprende nada formal, sino que quiere dejarlo todo. Entonces, el "apúrate" que se dicen entre ellas "tuerce" el cuidado del tiempo para su utilidad, dando paso a otro sentido. Que igual se aprende.

\section{Reflexionando}

La experiencia escolar de ambas familias está situada en casa a pesar de sus condiciones de vulnerabilidad. La distinción en el análisis entre actividades y aprendizajes resulta clave, pues permite identificar que la perspectiva bancaria fracasó en la formación de aprendizajes de lo formal, pero su realización, vía la interacción y los procesos de socialización familiar, pautó aprendizajes que devienen del currículum oculto. Así, las interacciones fueron trastocadas y puestas en función de actividades y aprendizajes, articulándose con relaciones de poder soportadas por el género y que no sufrieron modificación con la pandemia (incluso se reforzaron). Lo contradictorio es que esos aprendizajes son valorados por los vulnerables, en condición de dominación, y resultan igualmente de interés para el propio capital. Es 
también contradictorio que, entre los recovecos, pudieron darse aprendizajes otros. El virus enseña (De Sousa, 2020), pero con valores y organización, aun con sus límites, puede hacerlo de otras formas.

La pandemia ha confirmado que la crisis y la emergencia es la condición de normalidad en la que vivimos. Pero la pandemia nos recuerda que las pandemias que han de venir serán más fuertes en tanto el capital persista; depredar es una de sus condiciones para reproducirse (Harvey, 2020). Y sus efectos habrán de sentirse si las capacidades de respuesta del Estado están condicionadas por el neoliberalismo (De Souza, 2020). La conciencia colectiva activada como resultado de la pandemia (Fontana, 2020) aportará, pero disciplinada tendrá alcances limitados frente al reto que implica la interrupción de este ciclo. Construir alternativas puede ser utópico, pero su instauración como normalidad parece urgente. Los aprendizajes que "tuercen" el control para la utilidad, muy a pesar de las condiciones, representan una esperanza.

\section{Bibliografía}

Bowles, S. y Gintis, H. (1981). La instrucción escolar en la América capitalista. México: Siglo XXI.

De Sousa, B. (2020). La cruel pedagogía del virus. Buenos Aires: CLACSO.

Fontana, L. (2020). Pandemia y rearticulación de las relaciones sociales. Perifèria, revista de recerca i formació en antropología, 25(2), 101-114, https://doi.org/10.5565/rev/periferia. 770

Foucault, M. (2016). Vigilar y castigar. Nacimiento de la prisión (5a. reimpresión). México: Siglo XXI.

Giroux, H. (2004). Teoría y resistencia en educación, una pedagogía para la oposición. (1era. Ed.). México.

Harvey, D. (2020). Política anticapitalista en tiempos de coronavirus. En Agamben, G., Zizek, S., Nancy, J.L., Berardi, F., et. Al. Sopa de Wuhan (pp. 79-96). ASPO

Rogoff, B. (1993). Aprendices del pensamiento. El desarrollo cognitivo en el contexto social. Barcelona: Paidós. 